Original Article

\title{
Raster-stereographic evaluation of the effects of biomechanical foot orthoses in patients with scoliosis
}

\author{
So Min Park, MD ${ }^{1)}$, SAng-Ho Ahn, MD, PhD ${ }^{1,2)}$, A-Young Lee, MD, $\mathrm{PhD}^{3)}$, \\ In-SiK PARK, MS ${ }^{4}$, Yun-Woo ChO, MD, $\mathrm{PhD}^{1)^{*}}$ \\ 1) Department of Rehabilitation Medicine and Spine Center, Yeungnam University College of Medicine: \\ 170 Hyeonchung-no, Nam-gu, Daegu 42415, Republic of Korea \\ 2) Medical Devices Clinical Trial Center, Yeungnam University, Republic of Korea \\ 3) Department of Rehabilitation Medicine, J Hospital, Republic of Korea \\ 4) Korean Podiatry and Pedorthics Institute, Republic of Korea
}

\begin{abstract}
Purpose] Little is known about the effects of biomechanical foot orthoses in scoliosis, as determined by raster stereography. The objective of this study was to investigate the effect of individually manufactured biomechanical foot orthoses on scoliosis angle, trunk imbalance, and pelvic obliquity by comparing them with general insoles by using DIERS formetric 4 dimensional in patients with scoliosis. [Subjects and Methods] Twenty-six patients with scoliosis were recruited at Yeungnam University Hospital and allocated equally to one of two groups, the biomechanical foot orthoses group or the control group. Parameters, such as, trunk rotation, imbalance, and scoliosis angle, were obtained using a DIERS formetric 4D. [Results] Scoliosis angle, pelvic obliquity, and trunk imbalance were significantly different between the two groups and improved in the biomechanical foot orthoses group with time, but no significant improvement in any parameter was observed in the control group. [Conclusion] Biomechanical foot orthoses could be effective in patients with scoliosis, and DIERS formetric 4D provides a useful method for evaluating scoliosis parameters.

Key words: Scoliosis, Biomechanical foot orthosis, Formetric 4D
\end{abstract}

(This article was submitted Jan. 11, 2016, and was accepted Apr. 7, 2016)

\section{INTRODUCTION}

According to the Scoliosis Research Society, scoliosis is defined as the lateral deviation of the normal vertical curve of the spine by more than 10 degrees with or without deviation of the lateral curvature in the sagittal and axial views ${ }^{1,2)}$. The causes of scoliosis deformity are various. It can result from spinal structural pathologies or non-structural pathologies, such as lower extremity length discrepancy or pelvic imbalance ${ }^{3)}$. Treatment of scoliosis may involve conservative management or surgery. Surgery is recommended when spinal curvature exceeds 45 degrees ${ }^{4}$. The majority of patients receive conservative treatment, for example, orthoses, thoracolumbosacral orthoses (TLSO), or physical therapy, although the rationale for the selection of conservative treatment types is unclear.

Biomechanical foot orthoses (BFOs) are therapeutic custom-made tools, which are placed in shoes to control foot alignment during gait to allow normal foot motion and inhibit abnormal motion. From the biomechanical perspective, the body is multi-segmental, and segments interact strongly with each other. Furthermore, these interactions are important for musculoskeletal function. The pelvis is an important segment, and pelvic and lumbar positions are well-correlated ${ }^{5)}$. Irrespective of the plane of motion, foot alignment influences pelvic alignment ${ }^{6,7)}$, and alignment of the lower extremity, which involves the pelvis girdle, can be altered by forces acting on the feet ${ }^{7,8}$. In a previous study, postural and spinal adaptations were established in patients with scoliosis, using shoe lift heights of 5, 10, and $15 \mathrm{~mm}^{9}$. However, these shoe lifts were achieved

\footnotetext{
*Corresponding Author. Yun-Woo Cho (E-mail: tra5705@hanmail.net)

(C)2016 The Society of Physical Therapy Science. Published by IPEC Inc.

This is an open-access article distributed under the terms of the Creative Commons Attribution Non-Commercial No Derivatives (by-nc-nd) License $<$ http://creativecommons.org/licenses/by-nc-nd/4.0/>.
} 
using simple heel lifts, whereas BFOs are custom-designed for patients. Thus, BFOs rectify mal-alignment by stabilizing the foot and correcting mal-alignments of the spine and pelvis.

Standing whole spine radiographs are used to diagnose and follow-up spinal curve in scoliosis ${ }^{10)}$, and thus, Cobb's angle and other spinal parameters are measured using radiographic images. However, repetitive exposure to X-rays increases the risk of cancer development, including that of breast cancer ${ }^{11,12)}$. In contrast, surface topography offers a radiation free means of measuring spinal parameters. In particular, surface topography scanner DIERS formetric 4D (DIERS International $\mathrm{GmbH}$, Schlangenbad, Germany) can be used to measure trunk rotation, imbalance, and scoliosis angle, and has test-retest reproducibility comparable to that of radiography ${ }^{13)}$.

The parameters of scoliosis have been previously measured using a DIERS formetric 4D unit, but the effects of BFOs on scoliosis have not been previously assessed using this machine. The objective of this study was to confirm the effect of BFOs on scoliosis angle, trunk imbalance, and pelvic obliquity compared with general insoles by using a DIERS formetric 4D in patients with scoliosis.

\section{SUBJECTS AND METHODS}

Twenty-six patients with scoliosis were recruited from the Yeungnam University Hospital. Inclusion criteria included diagnosis of scoliosis with a Cobb angle of $\geq 10^{\circ}$ to $<45^{\circ}$ and age from 13 to 60 years. Exclusion criteria were: (1) severe scoliosis with a Cobb angle of $>45$ degrees, (2) leg length discrepancy of $>2 \mathrm{~cm}$, (3) pain of discal origin of VAS $>3$, (4) any lower extremity trauma or surgery history, (5) arthritis, (6) pregnancy, (7) spasm or spasticity of any muscle, and (8) a vestibular system problem affecting the regulation of posture. This study was approved by the Institutional Review Board of Yeungnam University Hospital and all subjects provided informed consent before participating in the study.

The study subjects were equally and randomly allocated to two groups: the BFO group $(\mathrm{n}=13)$ and the control group $(n=13)$, who used general insoles. In the BFO group, patients used a custom-made BFO for at least $3 \mathrm{~h} /$ day, and were evaluated before wearing a BFO and after 2 and 4 weeks of wearing a BFO. In the control group, general insoles were of the same height as the BFOs $(3 \mathrm{~mm})$, and were used for at least $3 \mathrm{~h} /$ day. Members of the control group were also evaluated before wearing a general insole and at 2 and 4 weeks after wearing an insole. Three measurements were taken at each evaluation and results were averaged. All evaluations were conducted by an independent, skilled examiner using a DIERS formetric 4D that used a photogrammetric recording of the back obtained by video raster stereography. The unit provides precise 3D shapes of patients' backs. Measurements were taken with patients undressed (to reveal buttocks for detection landmarks) and standing with both arms alongside the trunk and feet $20 \mathrm{~cm}$ apart. Images were obtained in 12 trials for total 6-sec and data were automatically analyzed. 'Trunk imbalance' was defined as lateral deviation of C7 (the most prominent vertebra) from midline of both lumbar dimples (posterior superior iliac spine, PSIS). 'Pelvic obliquity' was defined as the height difference between the lumbar dimples in the horizontal plane, and 'Scoliosis angle' was defined as the Cobb's angle ${ }^{9)}$ (Fig. 1).

The analysis was performed using SPSS Ver. 18.00, and significance was set at $\mathrm{p}$ values of $<0.05$. The paired t-test was used to compare the mean values.

\section{RESULTS}

Demographic and clinical characteristic of the 26 study subjects are provided in Table 1 . Mean ( \pm standard deviation) group ages, heights, body weights, scoliosis angles, trunk imbalances, and pelvic obliquities were not significantly different between the groups. Mean scoliosis angle was 17.6 \pm 4.7 in the BFO group and 19.6 \pm 7.9 in the control group. Mean trunk imbalance $(\mathrm{mm})$ was $10.7 \pm 6.3$ in the BFO group and $11.9 \pm 7.6$ in the control group, and mean pelvic obliquity was $10.6 \pm$ 10.4 in the BFO group and $5.7 \pm 2.3$ in the control group.

In the BFO group, the scoliosis angle and trunk imbalance at 2 and 4 week follow-ups and immediately after BFO fitting were significantly lower than at baseline $(\mathrm{p}<0.05)$ (Table 2$)$, and pelvic obliquity and VAS scores were significantly lower at 2 and 4 weeks than at baseline in the barefoot state $(p<0.05)$. In addition, there were significant reductions in the scoliosis angle, pelvic obliquity, and VAS scores in the BFO group between baseline and 2 weeks, and between 2 and 4 weeks $(p<0.05)$ (Table 2). In contrast, no significant reduction in these variables was observed at any time in the control group (Table 3 ).

\section{DISCUSSION}

The objective of this study was to evaluate the effects of BFO on spinal malalignment in patients with scoliosis by using a DIERS formetric 4D. In the BFO group, all parameters were significantly different during follow-up as compared with the initial barefoot state, but no significant difference was observed in the control group. Furthermore, in the BFO group, significant differences were observed in the scoliosis angle and pelvic obliquity when upon wearing BFOs.

In a previous study on patients with scoliosis, sacral tilt was decreased by a shoe lift, and this was accompanied by reductions in the lumbar and thoracolumbar spine angles ${ }^{9,14-16)}$. In addition, systematic postural adaptations have been demonstrated for shoe lifts and a significant correlation has been reported between the spinal curve reduction and the correction of leg length discrepancy ${ }^{9,17-20)}$. D'Amico et al. corrected the pelvic tilt and postural imbalance using an underfoot wedge, 


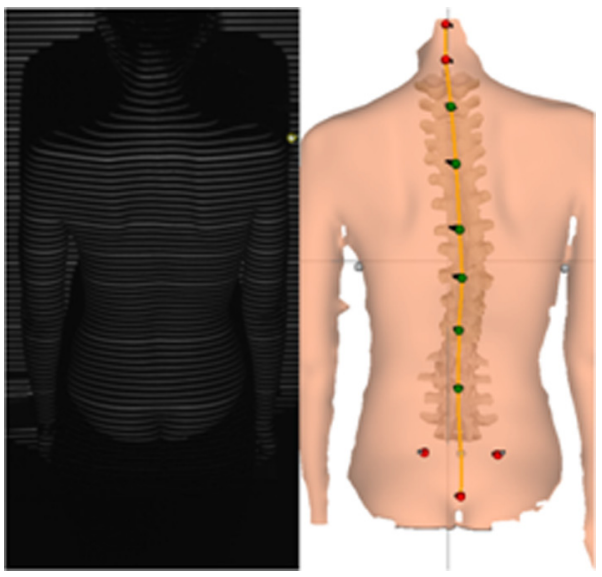

Table 1. Baseline patient characteristic and clinical parameters

\begin{tabular}{lcc}
\hline & \multicolumn{2}{c}{ Group } \\
\cline { 2 - 3 } & BFO $(\mathrm{n}=13)$ & Control $(\mathrm{n}=13)$ \\
\hline Gender $(\mathrm{M}, \mathrm{F})$ & 7,6 & 9,4 \\
Age $(\mathrm{yrs})$ & $35.8 \pm 17.4$ & $31.8 \pm 9.3$ \\
Height $(\mathrm{cm})$ & $167.3 \pm 9.0$ & $172.8 \pm 6.1$ \\
Weight $(\mathrm{kg})$ & $64.3 \pm 5.48$ & $64.1 \pm 11.4$ \\
Scoliosis angle $\left({ }^{\circ}\right)$ & $17.6 \pm 4.7$ & $19.6 \pm 7.9$ \\
Trunk imbalance $(\mathrm{mm})$ & $10.7 \pm 6.3$ & $11.9 \pm 7.6$ \\
Pelvic obliquity $(\mathrm{mm})$ & $10.6 \pm 10.4$ & $5.7 \pm 2.3$ \\
\hline
\end{tabular}

Values are presented as numbers or means \pm standard deviations BFO: biomechanical foot orthosis

Fig. 1. Projected line pattern on the back obtained by video raster stereography

Table 2. Parameters in the BFO group

\begin{tabular}{lcccccccc}
\hline & \multicolumn{3}{c}{ Initial barefoot } & \multicolumn{2}{c}{ Initial BFO } & \multicolumn{2}{c}{ BFO after 2 weeks } & \multicolumn{2}{c}{ BFO after 4 weeks } \\
\cline { 2 - 9 } & mean & SD & mean & SD & mean & SD & mean & SD \\
\hline Scoliosis angle $\left({ }^{\circ}\right)$ & 17.61 & 4.68 & $13.54^{*}$ & 4.12 & $12.7^{*}$ & 4.52 & $10.23^{*} \dagger+$ & 3.24 \\
Trunk imbalance $(\mathrm{mm})$ & 10.69 & 6.33 & $6.62^{*}$ & 4.49 & $5.92^{*}$ & 3.97 & $4.77^{*}$ & 2.74 \\
Pelvic obliquity $(\mathrm{mm})$ & 10.62 & 10.14 & 6.54 & 4.39 & $5.77^{*}$ & 3.70 & $3.92^{*} \dagger+$ & 3.59 \\
VAS & 4.46 & 1.27 & 4.46 & 1.27 & $3.42^{*} \dagger$ & 1.35 & $2.00^{*} \dagger+$ & 1.08 \\
\hline
\end{tabular}

SD: standard deviation; BFO: biomechanical foot orthosis; ${ }^{*} \mathrm{p}<0.05$, vs. initial barefoot values; $\uparrow \mathrm{p}<0.05$, compared to initial BFO; $\$ p<0.05$, compared to initial values

Table 3. Parameters in the control group

\begin{tabular}{lcccccccc}
\hline & \multicolumn{2}{c}{ Initial barefoot } & \multicolumn{2}{c}{ Initial insole } & \multicolumn{2}{c}{ insole after 2 weeks } & \multicolumn{2}{c}{ insole after 4 weeks } \\
\cline { 2 - 9 } & mean & SD & mean & SD & mean & SD & mean & SD \\
\hline Scoliosis angle $\left(^{\circ}\right)$ & 19.62 & 7.93 & 19.62 & 7.93 & 19.84 & 7.83 & 19.15 & 7.22 \\
Trunk imbalance $(\mathrm{mm})$ & 11.88 & 7.58 & 11.88 & 7.58 & 11.69 & 7.41 & 11.69 & 7.05 \\
Pelvic obliquity $(\mathrm{mm})$ & 5.69 & 2.29 & 5.69 & 2.29 & 6.23 & 2.24 & 5.62 & 2.53 \\
VAS & 3 & 0.71 & 3 & 0.71 & 3 & 0.71 & 3 & 0.71 \\
\hline
\end{tabular}

SD: standard deviation

because they focused on the correction of leg length discrepancy ${ }^{19}$. In the present study, we used custom-made foot orthoses that followed the natural contours of an individual's feet. Generally, rear-foot movement indicates the range of subtalar joint pronation within a foot, and excessive pronation of the subtalar joint is associated with injuries, and thus, neutral positioning of the subtalar joint is important for lower extremity function. Biomechanical foot orthoses reduce the excessive pronation of this joint by reorienting the rear-foot, which may be related to the realignment of the pelvic obliquity or imbalance ${ }^{21)}$. Coronal correction of the spinal alignment improved the trunk imbalance, and thus, we considered rear-foot correction, which included the correction of rear-foot pronation and supination. Reducing the differences in pelvic rotation as well as adjusting both rear feet in neutral position has also been suggested. We then confirmed that spinal postural variables were corrected.

Our evaluations were performed immediately after wearing shoe lifts or underfoot wedges and long-term follow-up tests were not conducted. In the BFO group, the pelvic obliquity and scoliosis angle significantly reduced with time. Scoliosis angles were corrected by reducing the sacral tilt and interaction or mobility of the musculoskeletal system ${ }^{9}$. In the BFO group, these parameters were significantly reduced at 4 weeks, which suggests that the musculoskeletal systems had adapted to the BFOs. The pelvic obliquity was a meaningful factor for scoliosis curves ${ }^{9,22)}$. Although the mechanism is unclear, it may be related to the pelvic stabilization and its effect on malalignments of adjacent vertebral bodies and changes in the functions of multiple back and abdominal muscles. Eventually, the unbalanced force on the vertebrae was redistributed ${ }^{9}$,23).

Many authors have suggested that increased exposure to ionizing radiation is a risk factor for cancer, especially for breast cancer ${ }^{24)}$. Repetitive X-ray exposure was reported to result in an overall increase of $8 \%$ in cancer risk, and a 3.9 fold 
increase in breast cancer risk ${ }^{25,26)}$. Accordingly, serial evaluations by plain radiography during follow up are unadvisable given a suitable alternative. Thus, in the present study, we used a DIERS formetric 4D, which provides a radiation-free means of obtaining surface topographies. It has been previously reported that the correlation between Cobb angles obtained by radiography and Scoliosis angles obtained topographically is significant ${ }^{24}$, 27), which was also observed in this study $(p<0.05)$. Thus, we measured the spinal parameters of scoliosis by DIERS formetric 4D that was persuasive. In addition, the strengths of DIERS formetric 4D were short test time, low cost, and no placement of any marking component, which reduced inspector measurement error.

The present study has some limitations that require consideration. First, the sample size was relatively small. Second, the follow-up period was only up to 4 weeks, and no long-term follow-up was performed, and thus, we cannot comment on the long-term effects of BFO use. Third, only three spinal parameters were evaluated, and we did not study the changes in pain scores or daily activities. Despite these shortcomings, this is the first study to investigate the effects of a biomechanical foot orthosis in patients with scoliosis by 'radiation-free' topography. Further large-scale long-term studies are needed to confirm our results. We believe BFO could be effective in patients with scoliosis, and that DIERS formetric 4D provides a useful means for evaluating scoliosis parameters.

\section{REFERENCES}

1) Scoliosis Research Society Web site: http://www.SRS.org/htm/glossary/medterms.htm. (Accessed Dec. 2003)

2) Lee M, Song C, Jo Y, et al.: The effects of core muscle release technique on lumbar spine deformation and low back pain. J Phys Ther Sci, 2015 , 27 : 1519-1522. [Medline] [CrossRef]

3) Van Goethem J, Van Campenhout A, van den Hauwe L, et al.: Scoliosis. Neuroimaging Clin N Am, 2007, 17: 105-115. [Medline] [CrossRef]

4) Haasbeek JF: Adolescent idiopathic scoliosis. Postgrad Med, 1997, 101: 207-209, 215-216. [Medline] [CrossRef]

5) Levine D, Whittle MW: The effects of pelvic movement on lumbar lordosis in the standing position. J Orthop Sports Phys Ther, 1996, 24: 130-135. [Medline] [CrossRef]

6) Gong WT, Ro HL, Park GD, et al.: The influence of pelvic adjustment on functional leg length inequality and foot pressure. J Phys Ther Sci, 2011, 23: 17-19. [CrossRef]

7) Khamis S, Yizhar Z: Effect of feet hyperpronation on pelvic alignment in a standing position. Gait Posture, 2007, 25: 127-134. [Medline] [CrossRef]

8) Yang JM, Lee JH, Lee DH: Effects of consecutive application of stretching, Schroth, and strengthening exercises on Cobb's angle and the rib hump in an adult with idiopathic scoliosis. J Phys Ther Sci, 2015, 27: 2667-2669. [Medline] [CrossRef]

9) Zabjek KF, Leroux MA, Coillard C, et al.: Acute postural adaptations induced by a shoe lift in idiopathic scoliosis patients. Eur Spine J, 2001, 10: 107-113. [Medline] [CrossRef]

10) Raso VJ, Lou E, Hill DL, et al.: Trunk distortion in adolescent idiopathic scoliosis. J Pediatr Orthop, 1998, 18: 222-226. [Medline] [CrossRef]

11) Boice JD Jr: Carcinogenesis - a synopsis of human experience with external exposure in medicine. Health Phys, 1988, 55: 621-630. [Medline] [CrossRef]

12) Doody MM, Lonstein JE, Stovall M, et al.: Breast cancer mortality after diagnostic radiography: findings from the U.S. Scoliosis Cohort Study. Spine, 2000, 25: 2052-2063. [Medline] [CrossRef]

13) Frerich JM, Hertzler K: Comparison of radiographic and surface topography measurements in adolescents with idiopathic scoliosis. Open Orthop, 2012, 6 : 261-265. [CrossRef]

14) Beaudoin L, Zabjek KF, Leroux MA, et al.: Acute systematic and variable postural adaptations induced by an orthopaedic shoe lift in control subjects. Eur Spine J, 1999, 8: 40-45. [Medline] [CrossRef]

15) Cummings G, Scholz JP, Barnes K: The effect of imposed leg length difference on pelvic bone symmetry. Spine, 1993, 18: 368-373. [Medline] [CrossRef]

16) Kwon YJ, Song M, Baek IH, et al.: The effect of simulating a leg-length discrepancy on pelvic position and spinal posture. J Phys Ther Sci, 2015, 27: 689-691. [Medline] [CrossRef]

17) Gibson PH, Papaioannou T, Kenwright J: The influence on the spine of leg-length discrepancy after femoral fracture. J Bone Joint Surg Br, 1983, 65: 584-587. [Medline]

18) Irvin RE: Reduction of lumbar scoliosis by use of a heel lift to level the sacral base. J Am Osteopath Assoc, 1991, 91: 34, 37-44. [Medline]

19) D'Amico M, Roncoletta P, Di Felice F, et al.: Leg length discrepancy in scoliotic patients. Stud Health Technol Inform, 2012, 176: 146-150. [Medline]

20) Cho BY, Yoon JG: The effect of gait training with shoe inserts on the improvement of pain and gait in sacroiliac joint patients. J Phys Ther Sci, 2015, 27: 2469-2471. [Medline] [CrossRef]

21) Kilmartin TE, Wallace WA: The scientific basis for the use of biomechanical foot orthoses in the treatment of lower limb sports injuries-a review of the literature. Br J Sports Med, 1994, 28: 180-184. [Medline] [CrossRef]

22) Specht DL, De Boer KF: Anatomical leg length inequality, scoliosis and lordotic curve in unselected clinic patients. J Manipulative Physiol Ther, 1991, 14: 368-375. [Medline]

23) Mente PL, Stokes IA, Spence H, et al.: Progression of vertebral wedging in an asymmetrically loaded rat tail model. Spine, 1997, 22: 1292-1296. [Medline] [CrossRef]

24) Ronckers CM, Doody MM, Lonstein JE, et al.: Multiple diagnostic X-rays for spine deformities and risk of breast cancer. Cancer Epidemiol Biomarkers Prev, 2008, 17: 605-613. [Medline] [CrossRef]

25) Ronckers CM, Land CE, Miller JS, et al.: Cancer mortality among women frequently exposed to radiographic examinations for spinal disorders. Radiat Res, 2010, 174: 83-90. [Medline] [CrossRef]

26) Ron E: Cancer risks from medical radiation. Health Phys, 2003, 85: 47-59. [Medline] [CrossRef]

27) Thometz JG, Lamdan R, Liu XC, et al.: Relationship between Quantec measurement and Cobb angle in patients with idiopathic scoliosis. J Pediatr Orthop, 2000, 20: 512-516. [Medline] [CrossRef] 